\title{
Maternal Perception of Body Mass Index and Dietary Habits Leading to Obesity Among Saudi School Aged Children a Comparative Study
}

\author{
Maha Mohammad Al Balawi ${ }^{1}$, Manal Fehade Al-Harbi ${ }^{2,}$, Sahar Mohammed Hassan Yakout ${ }^{3}$ \\ ${ }^{1}$ Center for Health Studies, Prince Sultan Military Medical, Riyadh, Saudi Arabia \\ ${ }^{2}$ Department of Maternity and Child Health Nursing, King Saud University, Riyadh, Saudi Arabia \\ ${ }^{3}$ Maternity and Gynaecologic Nursing, Alexandria University, Alexandria, Egypt \\ Email address: \\ Coobraw@gmail.com (M. M. Al Balawi), Maalwahbi@ksu.edu.sa (M. F. Al-Harbi), szamzam@ksu.edu.sa (S. M. H. Yakout) \\ ${ }^{*}$ Corresponding author
}

\section{To cite this article:}

Maha Mohammad Al Balawi, Manal Fehade Al-Harbi, Sahar Mohammed Hassan Yakout. Maternal Perception of Body Mass Index and Dietary Habits Leading to Obesity Among Saudi School Aged Children a Comparative Study. World Journal of Public Health.

Vol. 3, No. 1, 2018, pp. 23-31. doi: 10.11648/j.wjph.20180301.14

Received: March 31, 2018; Accepted: April 15, 2018; Published: May 17, 2018

\begin{abstract}
Background: Childhood obesity is one of the most severe public health problems of the 21 st century. Obesity is global, and it affects many low- and middle-income countries, especially in urban settings; its prevalence has increased at an alarming rate. The study was carried out in Prince Sultan Military Medical City and King Fahad Medical City in Riyadh, as well as the North West Armed Forces Hospital in Tabuk. Method: A quantitative correlative cross-sectional design was used. A non-probability sampling of mothers of school-age children $(n=300)$ was recruited. The questionnaire developed with two parts: tool I was a structured questionnaire, while tool II was the Child Feeding Questionnaire (CFQ). Result: The mean age of the mothers in Riyadh was 38.81 \pm 6.06 years old, while in Tabuk it was $40.3 \pm 5.8$ years old. Regarding maternal perception about their children, BMI $(80.7 \%, 82 \%)$ did not know the importance and detention of BMI and $80.7 \%$ not assessed before their BMI. There was a significant correlation between mothers' BMIs and their children's BMI. In comparison between maternal perception and actual BMI in Tabuk, $16.6 \%$ of mothers perceived their children to be underweight, but $4.8 \%$ of were underweight. Conclusion: It was concluded that over half of mother had fair to poor scores concerning knowledge about children's eating habits. Moreover, one-third of maternal perception and practices about the CFQ ranged from fair to poor. Thus, the researcher recommended applied nutritional counselling, and education should be provided; furthermore, children should be involved in group and diet workshops.
\end{abstract}

Keywords: Maternal Perception, Body Mass Index (BMI), Child Feeding Questionnaire (CFQ), Total Dietary Habits (TDH), Obesity, School-Aged Children

\section{Introduction}

The worldwide prevalence of overweight and obesity in children has increased at an alarming rate throughout the world. Obesity affects all levels of society, and thus it's described as a global epidemic. The highest rates of childhood obesity have been observed in developed countries, but its prevalence is also increasing in developing countries. The prevalence of childhood obesity is high in the Middle East. In Saudi Arabia, between 2000 and 2012, the rates of overweight and obesity among school-aged children increased by $23 \%$ and $9.3 \%$, respectively; one in every six children aged 6-18 years old is obese [1-3]. Although the national prevalence of overweight and obesity has been reported in adults and more recently in children information on regional differences in the Kingdom of Saudi Arabia (KSA) is scanty. The well-known regional variation in growth between regions in the KSA suggests diversity in the prevalence of nutritional disorders, including overweight and obesity [4-6].

Obesity represents a major health crisis that is affecting a large portion of society. It is considered to be a public health concern in both developed and developing countries. Since 
1980, the United States has experienced this problem in children and adolescents, with increases of obesity of $200 \%$ and $300 \%$ respectively $[7,8]$. According to the CDC, $17 \%$ of children suffer from overweight and obesity in the United States and surveys have revealed that nearly one out of every five US children is overweight; moreover, this number is increasing rapidly [8]. Approximately $10 \%$ of the world's school-aged children are estimated to be overweight or obese. In the United States, according to the National Health and Nutrition Examination, $18 \%$ of children were obese or overweight in 2009 and 2010. Also about 30\% of schoolaged children in the United States misperceive their weight status; this is more common in boys $(32.3 \%)$ than in girls (28\%). Another survey in the United States showed that $34.2 \%$ of school-aged children are obese (BMI $\geq 85$ th percentile), $17.7 \%$ are obese (BMI $\geq 95$ th percentile), and $6.8 \%$ are severely obese $(\mathrm{BMI} \geq 120$ percentage of the 95 th percentile or $\geq 35 \mathrm{~kg} / \mathrm{m}^{2}$ ) [9-11]. In the Kingdom of Saudi Arabia, overweight and obesity are the most common noncommunicable diseases found in the primary care setting. In 2010, data from a national sample of Saudi children showed that the prevalence of overweight and obesity in school-aged children (6 to 12 years) was $19.9 \%$ in boys and $19.2 \%$ in girls adulthood [12, 13]. In 2012, the National Health and Nutrition Examination Survey (NHANES) on childhood overweight and obesity among school-aged children showed that the prevalence of overweight was $34.2 \%$ and that of obesity was $17.7 \%$ [14-17]. Because childhood obesity often persists until adulthood, an increasing number of adults will be at an increased risk of these conditions, as well as of cardiovascular disease, osteoarthritis, and certain types of cancer [18-20]. Furthermore, eating habits have also changed, and current habits include low consumption of fruits, green vegetables, and milk; increasing consumption of snacks, sweets, and soft drinks; and skipping breakfast. These eating habits result in a continuous increase in adiposity among children [21]. In the case of children, mothers have been universally accepted to be primarily responsible for food Purchases, choices, and food preparation. An underlying problem with this approach is the dependence on maternal perception, and thus a parent must first be able to recognize when a child's diet is poor, and know how to make the necessary changes $[22,23]$. The lack of awareness and thus misperception for various healthrelated problems such as mothers not recognizing obesity in their children [24-26]. The way in which a mother perceives their child's diet quality is significant in ensuring a healthy diet for optimal development and disease prevention. Maternal feeding practices have an important role in the development of overweight and eating behaviors in schoolaged children; thus, they represent potential targets for effective prevention interventions to decrease child obesity $[27,28,29]$.

Body mass index (BMI) is a tool used to measure obesity that has been adopted by the International Obesity Task Force. BMI is a reliable indicator of body fatness for most children and teens [30]. BMI can be considered an alternative to direct measures of body fat. In addition, it is an inexpensive and easy-to-perform method of screening for weight categories that may lead to health problems [31]. When BMI is calculated for children and teens, the number is plotted on the Centers for Disease Control and Prevention (CDC) BMI-for-age growth charts (for either girls or boys) to obtain a percentile ranking, percentiles are the most commonly used indicator to assess the size and growth patterns of individual children in the United States [32, 33]. The maternity nurse, as a member of the healthcare team, has a unique role in raising awareness. She is responsible for helping Saudi mothers and their children to understand the problem of obesity and the dangerous consequences for physical, social, and psychological health with a view to changing their lifestyles. Although obesity is increasing in Saudi Arabia, previous studies have reported a high prevalence in some areas of the KSA but not all of them. In Saudi, with limited research that assessed mothers' perceptions regarding BMI and dietary habits, it is mandatory to investigate particular areas, such as the city of Tabuk in the northern region of Saudi Arabia to inform the community about the problem and highlight the mothers' role in mitigating it.

\section{Aim of the Study}

The aim of this study is to assess the maternal perceptions of BMI and dietary habits for their school-aged children as indicators in obesity screening in Tabuk and Riyadh. This aim will be attained through the following objectives:

1. Understand maternal perception for BMI and dietary habits leading to obesity among school-aged children.

2. Investigate maternal assessment of school-aged children's BMI and dietary habits.

3. Compare of the perceptions of mothers in Tabuk and Riyadh concerning BMI and dietary habits as indicators in obesity screening.

\section{Methods}

\subsection{Study Design and Setting}

A quantitative comparative, exploratory, correlative crosssectional design was used to conduct this study. The research was conducted at the general outpatient pediatric clinics in three hospitals which are Northwest Armed Forces Hospital in Tabuk, Prince Sultan Military Medical City (PSMMC) in Riyadh and King Fahad Medical City (KFMC) in Riyadh.

\subsection{Participants}

The data was collected from April to July 2017 with a purposive sampling. The sample included mothers who attend the pediatric clinics at the North West Armed Forces Hospital, SMMC, and KFMC. The participants of this study comprised 150 mothers of school-age children selected from Tabuk and 150 mothers of school-age children chosen from Riyadh. The sample size was calculated using the following equation: 


$$
Z^{2} \times p \times q / d^{2}
$$

Regarding the Maternal perception of body mass index and dietary habits leading to obesity among Saudi school children (p) was unknown, it was estimated to be $50 \%=0.5, q=1 p=$ 0.5 , and the value of 0.04 was chosen as an acceptable limit of precision $(d)$. At a $95 \%$ confidence limit, the calculated size of the sample was 400 participants. This number was reduced, as the number of participants reached 300 during the fieldwork. The eligibility criteria was educated Saudi mothers who had school-aged children (6-12 years) and available on the day of the interviews.

\subsection{Data Sources/Measurement}

The questionnaire developed with two parts. Part one was structured interview questionnaire sheet which developed by the researchers based on the literature review $[39,40]$ to collect data about mothers and their children, it consists of three parts: Part I covered the mother's data, such as age, level of education, and family income. Part II covered the child's demographic data, such as gender, age, education year, and birth order. Part III considered maternal perception about eating the healthy diet for their children, food style, eating habits, children's eating habits before going to school, the role of food in obesity and measurement of BMI.

Part two was as the following: 1) The Child Feeding Questionnaire (CFQ) was adopted from Birch et al. (2001) [6] to assess maternal perceptions and concerns regarding child obesity which consists of seven items; 2) Perceived responsibility (PR): This measure is a three-item subscale assessing mothers' perceptions of their responsibility for child feeding. The scale has response ratings of 1 (low feelings of responsibility) to 5 (high feelings of responsibility); 3) Perceived parent weight: is a measure of four-item subscale that considers parents' perceptions of their weight status history. The scores range from 1 (markedly underweight) to 5 (markedly overweight); 4) Perceived child weight: This six-item subscale measures parents' perceptions of their child's weight status history. The scores range from 1 (markedly underweight) to 5 (markedly overweight). The sixth item (parents' perception of their child's weight from 6th through 12th grade) was applied to mothers with children in these grades; 5) Parents' concerns about child weight: This is a three-item subscale that assesses parents' concerns about the child's risk of being overweight. Scores range from 1 (unconcerned) to 5 (highly concerned); 6) Restriction: This is an 8-item subscale that assesses the extent to which parents restrict their child's access to palatable foods. This measure considers the restriction of both the type and amount of food. Scores range from 1 (low restriction) to 5 (high restriction). 7) Pressure to eat: This is a four-item subscale that measures parents' tendency to pressure their children to eat by following certain behaviors, such as insisting that the child finish the food on his/her plate. Scores range from 1 (low) to 5 (high) levels of pressure. 8) Monitoring: This is a threeitem subscale that assesses the extent to which parents oversee their child's consumption of sweets, snack foods, and high-fat foods. Scores range from 1 (never) to 5 (always). The questionnaire forward translation was done by the study researchers then it was back-translated by two ArabicEnglish translators. Content validity of the structured questionnaire sheet was reviewed by five childhood obesity specialists who reviewed the questionnaire in English to ensure consistency and relevancy. Cronbach's alpha is a measure of internal consistency, it was determined to be 0.78 for the pilot trial. It was carried out on $10 \%$ of the total study sample to test the face validity and reliability of the tools. The tools were modified according to the results. The participants who were involved in the pilot study were excluded from the study sample. At the beginning of the interview, the purpose of the research was discussed with each attendee separately and, upon acceptance verbal and written consent were obtained. The participants were informed of their ability to terminate the interview at any point. No participants requested to stop the interview, the questionnaire for interviewing the participants was anonymous and confidential and had been pre-constructed for the study.

\subsection{Data Analysis}

Data were coded for entry and analysis using SPSS statistical software package version 20. Data were presented using descriptive statistics in the form of frequencies and percentages. Interval and ratio variables were shown in the form of means and standard deviations. Chi-square was used for nominal and ordinal data. The Pearson coefficient was used to test correlation. The significance level was set at $p<0.05$.

\section{Results}

The study descriptive data was presented in Table 1. Table 2 described mother's knowledge about eating their children healthy diet while Table 3 described maternal perception about their children's eating Habits.

Table 1. Socio-demographic Characteristics of the mothers and their children in Riyadh and Tabuk $(N=300)$.

\begin{tabular}{lllll}
\hline \multirow{2}{*}{ Variables } & \multicolumn{2}{l}{ Riyadh $(\mathbf{N}=\mathbf{1 5 0})$} & \multicolumn{2}{l}{ Tabuk $(\mathbf{N}=\mathbf{1 5 0})$} \\
\cline { 2 - 5 } & No & \% & No & \% \\
\hline Mothers & & & & \\
Age & 13 & 8.5 & 12 & 8.2 \\
$20-30$ & 86 & 56.2 & 77 & 52.4 \\
$31-40$ & 49 & 32.0 & 55 & 37.4 \\
$41-50$ & 5 & 3.3 & 3 & 2.0 \\
More than 50 & $38.6 \pm 6.1$ & & $40.3 \pm 5.87$ & \\
Mean \pm SD & & & & \\
Education & 0 & 0 & 0 & 0 \\
Illiterate & 2 & 1.3 & 3 & 2.0 \\
Read and write & 3 & 2.0 & 7 & 4.8 \\
Elementary school & 53 & 34.6 & 57 & 38.8 \\
Middle school & 15 & 9.8 & 22 & 15.0 \\
High School & 75 & 49.0 & 54 & 36.7 \\
University & 5 & 3.3 & 4 & 2.7 \\
Graduate & & & & \\
Income & 2 & 1.3 & 1 & 0.7 \\
Less than 4000 & & & & \\
\hline
\end{tabular}




\begin{tabular}{|c|c|c|c|c|}
\hline \multirow{2}{*}{ Variables } & \multicolumn{2}{|c|}{ Riyadh $(N=150)$} & \multicolumn{2}{|c|}{ Tabuk $(N=150)$} \\
\hline & No & $\%$ & No & $\%$ \\
\hline $4000-7000$ & 20 & 13.1 & 24 & 16.3 \\
\hline $7000-1000$ & 131 & 85.6 & 122 & 83.0 \\
\hline \multicolumn{5}{|c|}{ Mother occupation } \\
\hline Teacher & 50 & 32.6 & 29 & 19.7 \\
\hline Medical & 20 & 13 & 6 & 4 \\
\hline Housewife & 73 & 47.7 & 56 & 38 \\
\hline Other & 10 & 6.5 & 56 & 38 \\
\hline \multicolumn{5}{|l|}{ Children Age } \\
\hline $5-6$ & 22 & 14.4 & 27 & 18.4 \\
\hline $7-8$ & 39 & 25.5 & 29 & 19.7 \\
\hline $9-10$ & 50 & 32.7 & 52 & 35.4 \\
\hline $11-12$ & 42 & 27.5 & 39 & 26.5 \\
\hline \multicolumn{5}{|l|}{ Gender } \\
\hline Male & 66 & 43.1 & 62 & 42.2 \\
\hline Female & 87 & 56.9 & 85 & 57.8 \\
\hline \multicolumn{5}{|l|}{ Education } \\
\hline First & 22 & 14.4 & 28 & 19.0 \\
\hline Second & 38 & 24.8 & 23 & 15.6 \\
\hline Third & 6 & 3.9 & 9 & 6.1 \\
\hline Fourth & 18 & 11.8 & 17 & 11.6 \\
\hline Fifth & 31 & 20.3 & 36 & 24.5 \\
\hline Sixth & 38 & 24.8 & 34 & 23.1 \\
\hline
\end{tabular}

Table 2. Mother's Knowledge about eating, their children healthy Diet in Riyadh and Tabuk $(N=300)$.

\begin{tabular}{llllll}
\hline Variables & \multicolumn{2}{l}{ Riyadh $\mathbf{( N = 1 5 0 )}$} & \multicolumn{2}{l}{ Tabuk $\mathbf{( N = 1 5 0 )}$} & P \\
\hline & No & \% & No & \% & \\
\hline Eat more & & & & & \\
vegetables & & & & & 0.491 \\
Never & 2 & 1.3 & 0 & 0.0 & \\
Rarely & 2 & 4.6 & 9 & 6.1 & \\
Sometimes & 32 & 20.9 & 28 & 19.0 & \\
Usually & 112 & 73.2 & 110 & 74.8 & \\
Eat more Fruit & & & & & 0.329 \\
Never & & & & & \\
Rarely & 12 & 7.8 & 16 & 10.9 & \\
Sometimes & 10 & 6.5 & 14 & 9.5 & \\
Usually & 24 & 15.7 & 29 & 19.7 & \\
Eat Protein & 107 & 69.9 & 88 & 59.9 & \\
Never & 1 & 0.7 & 2 & 1.4 & \\
Rarely & 8 & 5.2 & 13 & 8.8 & \\
Sometimes & 19 & 12.4 & 24 & 16.3 & \\
Usually & 125 & 81.7 & 108 & 73.5 & \\
Drink milk and & & & & & \\
Juice & & & & & \\
Never & 1 & 0.7 & 1 & 0.467 \\
Rarely & 4 & 2.6 & 8 & 5.4 & \\
Sometimes & 12 & 7.8 & 16 & 10.9 & \\
Usually & 136 & 88.9 & 122 & 83.0 & \\
\hline
\end{tabular}

* Rating scale: $(1=$ never, $2=$ rarely, $3=$ sometimes, $4=$ usually $)$. The higher score, the more reliable.

Table 3. Maternal perception about their Children's Eating Habits $(N=300)$.

\begin{tabular}{lll}
\hline Variables & No & \% \\
\hline Number of meals per day & & \\
1 & 0 & 0 \\
2 & 1 & .3 \\
3 & 299 & 99.7 \\
Number of Snakes per day & & \\
1 & 22 & 7.3 \\
2 & 234 & 78 \\
3 & 44 & 14.7 \\
Number of breakfasts per week & & \\
Everyday & 229 & 76.3 \\
\hline
\end{tabular}

\begin{tabular}{lll}
\hline Variables & No & \% \\
\hline 4 times & 15 & 5.0 \\
3 times & 39 & 13.0 \\
Less than 3 times & 17 & 5.7 \\
Breakfast time & & \\
Before 7 am & 81 & 27.0 \\
$7-8$ am & 177 & 59.0 \\
$8-9$ am & 34 & 11.3 \\
After 9 m & 8 & 2.7 \\
Lunch time & & \\
$12-1$ pm & 35 & 11.7 \\
$1-2$ pm & 85 & 28.3 \\
$2-3$ pm & 125 & 41.7 \\
After 3 pm & 55 & 18.3 \\
Dinner time & & \\
Before bed time & 215 & 71.7 \\
At 7 pm & 85 & 28.3 \\
Child Meals per day & & \\
Breakfast & 283 & 94.3 \\
Snack after breakfast & 92 & 30.7 \\
Lunch & 194 & 64.7 \\
Snack after lunch & 221 & 73.7 \\
Dinner & 156 & 52.0 \\
Snack after dinner & 161 & 53.7 \\
\hline
\end{tabular}

* More than one answer

For the mother's knowledge about their children food style, more than half of mothers (57.3) add seasoning to their child food, while more than one-third of mothers didn't add seasoning to the food. More than half of children (51.3\%) had 3 cups of water daily, while only (4\%) of them had 1-2 cups daily. It was observed that more than two-thirds (67\%) of mothers had sometimes tried new foods with their child, while more than one-quarter $(27 \%)$ of them answered yes, and only $(6 \%)$ of them answered no. The majority $(83.3 \%)$ of mothers had allowed their children to pick up their food, while $(16.7 \%)$ of mothers they did not allowed. The result of children eat fast food was more than two-thirds (66.3\%), while more than one-third $(33.7 \%)$ they did not eat fast food. More than two-thirds $(66.7 \%)$ of children used to eat while watching TV, while more than one-third $(33.3 \%)$ of children did not watch. The maternal perception about food eaten by their children and lead to obesity, about two third (62\%) of mothers they did not know about which food dose their child eat and leads to obesity. While more than one-thirds (38\%) of mothers they know. Common type of food that lead to obesity was intake of juice (15.7\%), ice cream (30.3\%), and chips (24\%). Healthy food chosen by mothers were minority, meet, fish, and chicken $(1.3 \%)$, fresh vegetables $(1 \%)$, and cocked vegetables $(1.3 \%)$. The maternal perception about their Children's BMI, most $(97.7 \%)$, (95\%) of mothers their child weight and height assessed before, considerable high percentage of mothers $(80.7 \%)$ did not know the importance of measuring height and weight for their children. Regarding BMI 19.3\% BMI of their children assessed before and majority $(80.7 \%)$ not assessed. Only (18\%) know the definition of BMI and majority (82\%) gave wrong answer or did not know. The majority (87\%) of mothers did not know their children BMI and more than one-fifth (13\%) known. As regards self-perception of their child BMI, it was noticed that, $(14.7 \%)$ perceived their children as underweight, $(45 \%)$ 
perceived normal weight, (29\%) perceived their children overweight and $(11.3 \%)$ perceived as obesity. Also, about one third $(31 \%)$ of the sample indicated that they are responsible for feeding of their children most of the time, while only $(9 \%)$ of them were never responsible for the feeding. Concerning perceived parent weight, it was notified that, about three-quarters $(76 \%),(62.7 \%),(58 \%)$ of the sample subjects indicated that the parent weight was normal during childhood, adolescent and at present respectively. while only of $(0.3 \%, 2.7 \%, 0.3 \%)$ of perceived their weight markedly overweight. Maternal beliefs, attitudes and practices, regarding their school child feeding with focus on obesity proneness in children were analyzed by using sevenfactor model of CFQ. Two-thirds $(64.3 \%, 66.7 \%, 69 \%)$ of mothers monitoring their child eat for example sweets, snacks food, and high fat food respectively, while a minority never monitor $(2 \%, 0.7 \%, 0.1 \%)$ respectively. $(34.7 \%$, $34.5 \%$ ) of subjects reported that, they were responsible for deciding child's portion sizes and right kind of food respectively, while minority $(1 \%$, and $1.3 \%)$ never responsible about that. It was observed that, $(66.3 \%, 24.3 \%$, $20.7 \%$ ) perceived their child weight as normal in $2^{\text {nd }}$ grade, $5^{\text {th }}$ grade, and $6^{\text {th }}$ grade respectively, while $(10.3 \%, 9 \%$, $7.3 \%$ ) perceived them underweight in $2^{\text {nd }}, 5^{\text {th }}$, and $6^{\text {th }}$ grade respectively. Data showed also, about one-half (41.3\%, $47.7 \%, 52.3 \%$ ) of subjects very concerned about child if eating too much, having diet to maintain a desirable weight, overweighed respectively. While a minority $(1.7 \%, 0.3 \%$, $1 \%$ ) were unconcerned respectively. Regarding restriction, data showed that $(77.7 \%, 82.7 \%, 63.7 \%)$ of the study subjects restrict their children to eat many food, sweets, high fat food, and his/her favorite food respectively. Also, $(48.7 \%$, $59.3 \%, 41.7 \%$ ) of them keep some foods out of child's reach. About two-thirds $(35 \%, 31 \%)$ of mothers disagree to offer some sweets and foods as a reward for good behavior respectively, while $(11 \%)$ and $(17.3 \%)$ agree respectively. $(59.3 \%, 41.7 \%)$ of the mothers agree, that they were not guide or regulate child's eating. More than half (58.7\%) of mothers made pressure to their child to eat enough and more than two-thirds $(36.7 \%)$ of them made pressure to eat all of her/his plate. About one-half (43.3\%) not made pressure on their children, but she wants their children to eat much less than he/she should. While (26\%) made pressure if their children not hungry, try to get them to eat any way. There was a statistically significant positive correlation between factor total Score of seven-factor model of Child feeding Questionnaire and education $(p=0.010)$. There was a statistically significant positive correlation between actor Total Score of seven-factor model of Child feeding Questionnaire and income $(\mathrm{p}=0.000)$. This is indicated that the more educated mother, the better score of child feeding questionnaire. For estimated factor correlation for the sevenfactors model of child feeding questionnaire, the highest correlation between factors were between restriction and monitoring scales. Higher level of restriction was associated with greater monitoring. In addition, the pressure to eat scale was significant negatively associated with perceived child weight, indicating that parents who perceived their child as being thinner reported using higher level pressure to eat with child were $\mathrm{P}$ value $=(0.00), \mathrm{r}=(-.0357)$. There was a statistically significant positive correlation between factor perceived responsibility and perceived parent weight and child weight, concern about child weight restriction and monitoring. Concern about child weight was statistically significant with restriction and monitoring. there was statistically significant relationship between Total Score Dietary Habits Questionnaire and Children's BMI $(\mathrm{p}=0.00)$. (65.4\%) of mothers CFQ were fair of their children had normal weight. While $29.9 \%, 4.7 \&$ overweight and obese respectively. Good total score of $46 \%$ had normal weight, while $51.8 \%$ overweight and obese respectively. There was statistical significant difference, were $\mathrm{P}$ value $=0.00$. Comparison between maternal perception and actual BMI in Riyadh and Tabuk is in Table 4.

Table 4. Comparison between maternal perception and actual BMI in Riyadh and Tabuk $(N=300)$.

\begin{tabular}{|c|c|c|c|c|c|c|c|c|c|}
\hline \multirow{2}{*}{$\begin{array}{l}\text { Children } \\
\text { BMI }\end{array}$} & \multicolumn{2}{|c|}{ Tabuk } & \multicolumn{2}{|c|}{ Riyadh } & \multicolumn{2}{|c|}{ Tabuk } & \multicolumn{2}{|c|}{ Riyadh } & \multirow{2}{*}{$\mathbf{P}$} \\
\hline & No & $\%$ & No & $\%$ & No & $\%$ & No & $\%$ & \\
\hline $\begin{array}{l}\text { Under } \\
\text { weight }\end{array}$ & 26 & 16.6 & 19 & 12.6 & 7 & 4.8 & 10 & 6.5 & 0.127 \\
\hline $\begin{array}{l}\text { Normal } \\
\text { Weight }\end{array}$ & 69 & 46 & 66 & 44 & 82 & 55.8 & 84 & 54.9 & \\
\hline Over weight & 43 & 28.6 & 44 & 29.3 & 44 & 29.9 & 52 & 34 & \\
\hline Obese & 15 & 10 & 19 & 12.6 & 14 & 9.5 & 7 & 4.6 & \\
\hline
\end{tabular}

\section{Discussion}

The prevalence of childhood obesity has increased over the past three decades due to poor eating habits and eating high amounts of high-calorie foods, leading to childhood obesity. Prevention of childhood obesity is the best way to decrease the risk of physical morbidities and psychological problems. Parents are crucial in controlling the child's environment and implementing effective prevention strategies. Obese children face many physical, medical, and metabolic complications, such as diabetes mellitus, hypertension, dyslipidemia, nonalcoholic fatty liver disease, and orthopedic disorders [34] The leading cause of obesity is not fully understood, but previous researchers have confirmed that obesity occurs when the energy intake exceeds the energy expenditure [35]. The mean age of the mothers in Riyadh was $38.81 \pm 6.06$ years, while in Tabuk, it was $40.3 \pm 5.8$ years which is approximate to the results of Pakpour et al. (2011), [14] who reported that the mean ages of mothers for the control and intervention groups were $33.2 \pm 6.4$ and $34.1 \pm 3.8$ years, respectively. Regarding the mothers' education, $49 \%$ of subjects had completed their university education in Riyadh, while $38.8 \%$ had completed only their middle school education in Tabuk. This study could not discern a significant association between childhood obesity and maternal occupational or educational level; this result is dissimilar to that of Warschburger and Kröller (2012), [36] who reported that mother education and occupation, as well as family income, have significant effects on mothers' accuracy in 
identifying obesity.

About $47.7 \%$ and $38 \%$ of mothers in this study were housewives, and $32.6 \%$ and $19.7 \%$ were teachers in Riyadh and Tabuk, respectively. This finding is by Vázquez (2013), [37] who stated that living in a non-intact family environment, low maternal educational level, and having a mother who works outside of the home encourages the development of risk behaviors for health in children, such as obesity. The mother's level of knowledge affects the association between obesity and eating habits, and children who have good dietary habits are known to be healthier. Many factors are suspected to influence maternal food choice; mothers with good dietary knowledge are more likely to teach their children about healthy food choices. The results of the present study show that about three-quarters $(73.2 \%$, $74.8 \%$, respectively) of mothers usually encouraged their children to eat more vegetables in Riyadh and Tabuk. There was no significant difference between the two cities. Meanwhile, about two-thirds $(69.9 \%, 59.9 \%$, respectively) usually encouraged their children to eat fruits in Riyadh and Tabuk; these results are by those of Yabanc1, Nurcan, and Suzan (2014), [38] whose study included 302 mothers of students. Their results indicated that $64.7 \%$ of mothers always made their children eat at least three portions of vegetables a day, while $62.4 \%$ always encouraged their children to eat more fruits.

Many of the mothers with more knowledge about the eating habits of their children had normal weight. Also, the mothers with higher knowledge provided their children with a healthier diet (e.g., vegetables, fruit, juices, and fewer soft drinks and fast foods) than the mothers with lower knowledge about nutrition. This result could be explained in that mothers who were more educated had more knowledge about eating habits. Perceived mother modeling, perceived mother support, and perceived fruit and vegetable availability were significant predictors of fruit and vegetable consumption. The relationship between perceived mother support and fruit and vegetable consumption was mediated by self-efficacy [39]. In this study, breakfast was considered "the most important meal of the day." It was found that $76.3 \%$ had breakfast every day, while only $13 \%$ had breakfast three times per week exactly. This is similar to the results of Tylor (2007), [40] who reported that only $(30 \%)$ of children ate breakfast before leaving home. When a child consumes sufficient food at the beginning of the day, this helps the body to obtain the nutrients it needs. The data showed that more than half of the children $(51.3 \%)$ consumed three cups of water daily, while $4 \%$ had two cups daily. This result is by Drewnowski and Rhem (2013), [41] who reported that water consumption among American children was $49.6 \%$, which is lacking. It is dangerous because water represents a critical nutrient whose absence will be lethal within days. The data also showed that nearly two-thirds $(66.3 \%)$ of children ate fast food, while more than one-third (33.7\%) did not eat fast food. This result agrees with that of Denney and Okely (2008), [42] who stated that the prevalence of consumption of fast food was higher among boys than girls. The fast-food consumption rate for boys was $19.6 \%$ in grade $6,15.7 \%$ in grade 8 , and $16.0 \%$ in grade 10 . Among girls, grade 10 students were most likely to report eating fast food at least once per week $(14.0 \%)$, while $9.2 \%$ of grade 8 and $10.2 \%$ of grade 6 girls consumed fast food. About children's eating habits before going to school, it was observed that more than one-third of children had taken breakfast before going to school, while more than one-half did not take breakfast before going to school. This may be due to the time of intake of breakfast or choice of food by school children, to identify reasons behind usual breakfast practices and explore the attitude of mothers about breakfast. This is in agreement with Senanayake et al. (2009), [43] whose study result showed only $30 \%$ ate breakfast and $70 \%$ left home without breakfast. Regarding the maternal perception of their children's weight and their actual BMI, it was found that $72 \%$ and $73.7 \%$ of mothers in Tabouk and Riyadh, respectively, perceived their children to be underweight when their BMI was normal. These findings agree with those of Rietmeijer and Paluis (2012), [44] who reported that $47.7 \%$ of their children were incorrectly perceived as having normal weight by their parents. This can be explained by Saudi women's fear of the evil eye, which causes them to see their children as underweight when they are in fact normal. The study results showed significant a statistically significant relationship between children's BMIs and their mother's BMIs. Obese and overweight children had parents who were heavier than normal. Another study indicated that mothers' BMIs are strong predictors of children's BMIs. [44, 45]

In the present study, about more than two-thirds (67.5\%) of the children had practiced exercise and had normal weight. About one-third (33.3\%) of children did not engage in physical exercise, and they were obese. This could be explained in that exercise will increase energy requirements and decrease fat deposits. Hilbert et al. (2007),[46] reported that lack of physical exercise was one of the main causes of obesity. AL-Rukban (2003), [47] studied a group of subjects age 12-20 years from Saudi Arabia to assess the relationship between obesity and sociodemographic data and physical activities, and he reported that family history and lack of physical activity were associated with adolescent obesity.

The present study showed there was a statistically significant positive correlation between child age, child weight, and birth order $(p=0.00)$. The first and last children within the families were more likely to be obese than the children born in between. These findings agreed with Lafta and Kadhim., 2005, [48] They reported significant associations between overweight, age, and number and order of the children. Teaching healthy behaviors at school age is important since change becomes more difficult with aging. Behaviors involving physical activity and nutrition are the cornerstone of obesity prevention in children and youth. Families and schools are the two most critical links in providing the foundation for those behaviors.

According to Keller et al. (2006), [49] older mothers were more likely to perceive their children as being more 
substantial than younger mothers. Older mothers were also more likely to monitor children's fat intake in siblings than more adolescent mothers. This finding conflicts with the present research results, which showed no statistically significant positive correlation between the total score of the seven-factor model of the CFQ and mother age ( $p=0.383)$.

Regarding the maternal perception about factors related to children's obesity, Moore (2009), [50] reported that the majority of mothers exhibited poor eating behavior (96.6\%). The lack of parental control $(86.2 \%)$, eating too much $(81 \%)$, hormonal problems $(33.3 \%)$, and peer pressure $(23.3 \%)$, which were considered the most significant causes of childhood obesity. The present study revealed that most mothers $(91 \%)$ perceived that increased food intake leads to obesity, while more than one-third $(35 \%)$ perceived that obesity is caused by peer pressure. Also, about three-quarters $(73.7 \%, 71.7 \%$, and $71.7 \%)$ of mothers perceived that unhealthy diet, sedentary lifestyle, and food caused child obesity.

Webber et al. (2010) [51] reported that higher child weight was associated with higher "pressure to eat" and lower "restriction" factors. Restriction increased as maternal awareness about overweight increased, and maternal concern about overweight was associated with childhood obesity and restriction. Use of pressure increased when the mothers perceived their children to be thinner, but the perceived weight was not associated with child weight status and maternal pressure to eat.

Monitoring was not associated with childhood obesity or maternal perception of weight. This study supported my findings on maternal beliefs, attitudes and practices regarding their school child are eating with a focus on obesity proneness. The data showed that about one-half $(41.3 \%$, $47.7 \%, 52.3 \%$ ) of mothers were very concerned about whether their children were overeating or were overweight. Meanwhile, a few mothers $(1.7 \%, 0.3 \%, 1 \%)$ were unconcerned about these issues. Obesity was the most common diet-related health disorder among the parents of the subjects, followed by diabetes mellitus.

The data showed that if both parents were obese, $70 \%$ of the subjects were also obese. This could be explained in that obesity aggregates within families because of shared genes and environments. Children may have had the same dietary habits and lifestyles as their parents, such as eating highcalorie foods and neglecting exercise. [46]

Regarding maternal dietary restriction, data showed that $77.7 \%, 82.7 \%$, and $63.7 \%$ of the study subjects restricted their children's intake of sweets, high-fat foods, and their favorite foods, respectively. Also, 48.7\%, 59.3\%, and 41.7\% of them kept some foods out of their children's reach. About two-thirds, $35 \%$ and $31 \%$ of mothers disagreed with offering sweets and other foods as a reward for good behavior, respectively, while $11 \%$ and $17.3 \%$ agreed with this practice. Furthermore, $59.3 \%$ and $41.7 \%$ of the mothers agreed that they did not guide or regulate their children's eating. More than half $(58.7 \%)$ of mothers pressured their children to eat enough, and more than two-thirds $(36.7 \%)$ of them pressured their children to clean their plates. Thus, the results of the research study revealed that more than one-third of mothers had fair to poor dietary habits, and more than one-third their practices, attitudes, and beliefs about child feeding. This is because mothers' imposition of control in feeding is prompted by perception and concerns regarding the child's risk of obesity. Maternal restriction and pressure to eat affect self-confidence related to eating in the child. The implication for pediatric nurse: as the pediatric nurse has a unique role in the health care delivery system and the role as facilitators to deliver health to the public. Thus, they can educate mother and increase awareness about the causes and consequences of childhood obesity.

\section{Conclusion}

Based on the findings of the present study, it is concluded that more than one-half of mothers' total scores on knowledge about children's eating habits ranged from fair to poor. Furthermore, more than one-third of maternal practices, attitudes, and beliefs as assessed by the CFQ ranged between fair and poor. A high proportion of mothers did not know about which foods their children eat that lead to obesity. Also, there was significant discrepancies between children's actual weight status and perceptions among mother of children's weight, particularly for obesity/overweight. This tendency needs more attention as, school-aged children tend to have a higher prevalence of obesity-related conditions, particularly CVD, at a younger age. There was a tendency among less-educated mothers to perceive their children's overweight/obesity status. A higher percentage of mothers with higher education were able to recognize their children's overweight or obesity than mothers with less education.

\section{Recommendations}

1. Nutrition and physical education programs for schoolaged children should focus on mother role modeling in promoting a healthy lifestyle and good dietary habits.

2. Educational school health programs should be implemented to affect the lives of school-aged children by improving health-related knowledge, attitudes, and the skills needed to learn healthy behaviors and good health outcomes.

3. Strategies should be implemented to achieve positive health outcomes for Saudi school-aged children by promoting regular physical activity. It is a fundamental public health strategy that has been identified to have notable effects on health improvement at the individual and societal levels.

4. Free drinking water should be made available to all students, and the sale of drinks with added sugars, like sodas and juices, should be limited in schools;

5. Interventions should focus only on modifiable behaviors (e.g., physical activity, limited intake of sugar-sweetened beverages, teasing, time spent watching television). 
6. Mothers should be provided with information to feed their children, especially when they are concerned about their children's weight. Workshops may also be necessary in some cases. Heighten mother's perception; mothers should be educated to monitor school-aged children's BMI for age; in this way, issues can be identified in a timely fashion. Using sketches will help to determine overweight children; and

7. Further comprehensive research should be undertaken to study the lifestyles of families of obese children and how to prevent obesity.

\section{References}

[1] Qazi IA, Charoo BA, Sheikh MA. Childhood obesity. Indian J Endocrinol Metab. 2010 Jan; 14(1):19.

[2] Karnik S, Kanekar A. Childhood obesity: a global public health crisis. Int J Prev Med. 2012; 3(1). 2015 Mar 20:1-7.

[3] Al-Ghamdi S. The association between watching television and obesity in children of school-age in Saudi Arabia. J Fam Community Med. 2013; 20(2):83.

[4] Sutherland E. Obesity and asthma. Immunol Allergy Clin North Am. 2008; 28(3):589-602.

[5] Taylor E. Orthopedic complications of overweight in children and adolescents. Pediatrics. 2006; 117(6):2167-74.

[6] Birch LL, Fisher JO, Grimm-Thomas K, Markey CN, Sawyer R, Johnson SL. Confirmatory factor analysis of the Child Feeding Questionnaire: a measure of parental attitudes, beliefs and practices about child feeding and obesity proneness. Appetite. 2001; 36(3):201-10.

[7] Ogden C, Carroll M, Kit B, Flegal K. Prevalence of childhood and adult obesity in the United States, 2011-2012. Survey of Anesthesiol. 2014; 58(4):206.

[8] Mathers C, Fat DM, Boerma JT. Organization WH. Boerma JT. 2008.

[9] Wang Y, Lobstein TIM. Worldwide trends in childhood overweight and obesity. Int J Pediatr Obesity. 2006; 1(1):1125.

[10] Skinner AC, Skelton JA. Prevalence and trends in obesity and severe obesity among children in the United States, 19992012. JAMA Pediatr. 2014.

[11] Sarafrazi N, Hughes JP, Borrud L, Burt V, Paulose-Ram R. Perception of weight status in US children and adolescents aged 8-15 years, 2005-2012. NCHS data brief. 2014 Jul (158):1-7.

[12] El Mouzan M, Foster P, Al Herbish A, Al Salloum A, Al Omer A, Qurachi M, et al. Prevalence of overweight and obesity in Saudi children and adolescents. Ann Saudi Med. 2010; 30(3):203.

[13] Laitinen J, Power C, Järvelin MR. Family social class, maternal body mass index, childhood body mass index, and age at menarche as predictors of adult obesity-. The American journal of clinical nutrition. $2001 \mathrm{Sep} 1$; 74(3):287-94.

[14] Pakpour A. Mothers' perception of obesity in schoolchildren: a survey and the impact of an educational intervention. Jornal de pediatria. 2011; 87(2).

[15] Han J, Lawlor D, Kimm S. Childhood obesity. Lancet. 2010; 375(9727):1737-48.

[16] Taber DR, Chriqui JF, Powell L, Chaloupka FJ. Association between state laws governing school meal nutrition content and student weight status: implications for new USDA school meal standards. JAMA Pediatr. 2013; 167(6):513-9.

[17] Ogden CL. Obesity and socioeconomic status in children and adolescents: United States, 2005-2008 [Internet]. [Place unknown]: Centers for Disease Control and Prevention [2010 Dec 14. 2014 Oct 15]. Available from: http://www.cdc.gov/nchs/data/databriefs/db51.htm

[18] Kalra G, De Sousa A, Sonavane S, Shah N. Psychological issues in pediatric obesity. Ind Psychiatry J. 2012 Jan; 21(1):11.

[19] Hancox RJ, Poulton R. Watching television is associated with childhood obesity: But is it clinically important? Int J Obes. 2006; 30:171-5. [PubMed]

[20] Marmot M. Food, Nutrition, Physical Activity, and the Prevention of Cancer: a Global Perspective [Internet]. [Place unknown]: World Cancer Research Fund/American Institute for Cancer Research; 2007 Available from: http://www.aicr.org/assets/docs/pdf/reports/Second_Expert_Re port.pdf

[21] Rodgers RF, Paxton SJ, Massey R, Campbell KJ, Wertheim $\mathrm{EH}$, Skouteris H, Gibbons K. Maternal feeding practices predict weight gain and obesogenic eating behaviors in young children: a prospective study. International Journal of Behavioral Nutrition and Physical Activity. 2013 Dec;10(1):24.

[22] Harrison, K., \& Marske, A. L. (2005). Nutritional content of foods advertised during the television programs children watch most. American Journal of Public Health, 95(9), 15681574 .

[23] Drewnowski, A. (2009). Obesity, diets, and social inequalities. Nutrition reviews, 67(suppl 1), S36-S39.

[24] Garrett-Wright, D. (2011). Parental perception of preschool child body weight. Journal of pediatric nursing, 26(5), 435445 .

[25] He, M., \& Evans, A. (2007). Are parents aware that their children are overweight or obese? Do they care? Canadian Family Physician, 53(9), 1493-1499.

[26] Corder, K., van Sluijs, E. M., McMinn, A. M., Ekelund, U., Cassidy, A., \& Griffin, S. J. (2010). Perception versus reality: Awareness of physical activity levels of British children. American journal of preventive medicine, 38(1)

[27] Lindsay A, Sussner K, Kim J, Gortmaker S. The role of parents in preventing childhood obesity. Future Child. 2006; 16(1):169-86

[28] Wardle J, Carnell S, Cooke L. Parental control over feeding and children fruit and vegetable intake: how are they related? J Am Diet Assoc. 2005; 105(2):227-32.

[29] Daniels S. Overweight in children and adolescents: pathophysiology, consequences, prevention, and treatment. Circulation. 2005; 111(15):1999-2001. 
[30] Whitlock E. Screening and interventions for childhood overweight: a summary of evidence for the US preventive services task force. Pediatrics. 2005: 116(1):125-144.

[31] Al-Rethaiaa AS, Fahmy AE, Al-Shwaiyat NM. Obesity and eating habits among college students in Saudi Arabia: A cross sectional study. Nutr J. 2010; 9: 39. [PMC free article] [PubMed]

[32] Centers for Disease Control and Prevention. Overview of CDC growth charts [Internet]. [Place unknown]: Centers for Disease Control and Prevention, n.d. [2014 Oct 31]. Available from:

http://www.cdc.gov/nccdphp/dnpa/growthcharts/training/mod ules/module $2 /$ text/p age 1 a.htm

[33] Al-Nozha M. Obesity in Saudi Arabia. Saudi Med J. 2015; 26(5):824-9.

[34] Lee YS. Consequences of childhood obesity. Ann Acad Med Singapore. 2009; 38(1):75-7.

[35] Dehghan M, Akhtar-Danesh N, Merchant A. Nutr J. 2005; 4(1):24.

[36] Warschburger P, Kröller K. Childhood overweight and obesity: maternal perceptions of the time for engaging in child weight management. BMC Public Health. 2012; 12(1):295.

[37] Vázquez-Nava F, Treviño-Garcia-Manzo N, VázquezRodríguez C, Vázquez- Rodríguez E. Association between family structure, maternal education level, and maternal employment with sedentary lifestyle in primary school-age children. Jornal de Pediatria.2013; 89(2):145

[38] Yabancı N, Kısaç I, Karakuş SS. The effects of mother's nutritional knowledge on attitudes and behaviors of children about nutrition. Procedia Soc Behav Sci [Internet]. 2014; 116: 4477-4481.

[39] Young, E., Fors, S., \& Hayes, D. (2004). Associations between Perceived Parent Behaviors and Middle School Student Fruit and Vegetable Consumption. Journal of Nutrition Education And Behavior, 36(1), 2-12. http://dx.doi.org/10.1016/s1499- 4046(06)60122-x

[40] Taylor E. Orthopedic complications of overweight in children and adolescents. Pediatrics. 2006; 117(6):2167-74.
[41] Drewnowski A, Rehm C, Constant F. Water and beverage consumption among children age 4-13y in the United States: analyses of 2005-2010 NHANES data. Nutr J. 2013; 12(1):85.

[42] Denney-Wilson E, D. Okely A. Influences on consumption of soft drinks and fast foods in adolescents. Asia Pac J Clin Nutr. 2009; 18(3):447-52.

[43] Senanayake M, Parakramadasa H. A survey of breakfast practices of 4-12 year old children. Sri Lanka J Child Health. $2009 ; 37(4)$.

[44] Bralić I, Vrdoljak J, Kovačić V. Associations between parental and child overweight and obesity. Coll Antropol. 2005; 29(2):481-6.

[45] Abrevaya J, Tang H. Body mass index in families: spousal correlation, endogeneity, and intergenerational transmission. Empir Econ. 2010; 41(3):841-64.

[46] Hilbert A, Rief W, Braehler E. What determines public support of obesity prevention? J Epidemiology Community Health. 2007 Jul; 61(7):585-90.

[47] Al-Rukban MO. Obesity among Saudi male adolescents in Riyadh, Saudi Arabia. Saudi Med J. 2003; 24(1):27-33.

[48] Lafta RK, Kadhim MJ. Childhood obesity in Iraq: prevalence and possible risk factors. Ann Saudi Med. 2005 Mar; 25(5):389.

[49] Keller K, Pietrobelli A, Johnson S, Faith M. Maternal restriction of children's eating and encouragements to eat as the "non-shared environment": a pilot study using the child feeding questionnaire. Int J Obes Relat Metab Disord. 2006; 30(11):1670-5.

[50] Moore B. Assessment of children: how to use repeated measures of body mass index (BMI) to assess and prevent obesity in children. Shape Up America; 2009.

[51] Webber L, Hill C, Cooke L, Carnell S, Wardle J. Associations between child weight and maternal feeding styles are mediated by maternal perceptions and concerns. Eur J Clin Nutr. 2010; 64(3):259-65. 